Original Research Article

\title{
Evaluation of prescription pattern and quality of life in postmenopausal osteoporosis: a cross sectional study
}

\author{
Siddharth Pravin Agrawal ${ }^{1}$, Suhani V. Patel ${ }^{2 *}$, Supriya Malhotra ${ }^{2}$, Pankaj R. Patel ${ }^{3}$
}

\begin{abstract}
${ }^{1}$ M.B.B.S, ${ }^{2}$ Department of Orthopedics, Smt. Nathiba Hargovandas Lakhmichand Municipal Medical College, Ahmedabad, Gujarat, India

Received: 03 July 2019

Revised: 07 July 2019

Accepted: 09 July 2019

*Correspondence to: Dr. Suhani V. Patel, Email: suni2121986@ gmail.com
\end{abstract} Pharmacology, ${ }^{3}$ Department of

Copyright: (C) the author(s), publisher and licensee Medip Academy. This is an openaccess article distributed under the terms of the Creative Commons Attribution NonCommercial License, which permits unrestricted noncommercial use, distribution, and reproduction in any medium, provided the original work is properly cited.

\begin{abstract}
Background: Osteoporosis (OP) is a silently progressing metabolic bone disease that results in loss of mineralized bone and subsequent fractures with minor trauma. Fracture related pain and physical inability to perform activities of daily living can lead to psychological consequences that impair Quality of Life (QoF). However, much less is known about Indian scenario. Hence, our study becomes imperative. Aim of this study to the drug utilization pattern and to analyze Quality of life of postmenopausal women suffering from osteoporosis.

Methods: An analytical cross-sectional study was done on 91 post-menopausal osteoporotic women. Drug utilization pattern was evaluated. Pre-validated QUALEFFO-31 questionnaire was administered to each patient to record patient's perceived QoL. Scores were calculated according to the algorithm. Higher scores indicated poor QoL. The collected data was analyzed with SPSS software (version 23)and p value $\leq 0.05$ was considered as statistically significant. Results: The mean age group of presenting patients was $56.2 \pm 6.6$ years. All the patients received Calcium and vitamin D supplements and non-steroidal antiinflammatory drugs for pain relief. But only $33 \%$ of the patients received any one of the bisphosphonates (BP). For analysis, patients were grouped into Group$1(n=60)$ who did not and Group-2 $(n=31)$ who did receive a BP. QOL analysis showed that pain domain was affected the most. Also, patients in Group 2 reported worse score in all the domains in comparison to Group $1(\mathrm{P}<0.05)$. It is likely that BP might need more time to show considerable effect or because it was added only to those patients who already had more complaints and could afford the high cost.

Conclusion: BP in spite of being the drug of choice for OP is used less commonly in India. OP causes pain and physical debilitation with detrimental effect on mental health. Longer duration prospective studies are needed to study the association of QoL and use of BP in OP patients.
\end{abstract}

Keywords: Drug utilization study, Epidemiology, Osteoporosis

\section{INTRODUCTION}

The word Osteoporosis (OP) literally translates as "porous bones" and is the most common bone disease found in humans. It is a silently progressing metabolic bone disease causing considerable cause of morbidity and mortality. ${ }^{1-3}$ An Indian studyestimated the prevalence of osteoporosis as $24.6 \%$ in men and $42.5 \%$ in women above 50 years of age. ${ }^{4}$
As age advances, there is continuous loss of trabeculae in bone, leading to imbalance between bone breakdown and build up. And in postmenopausal females, the deficiency of hormone estrogen causes exaggerated loss in bone mass, which in turn causes fractures after minor trauma, especially of spinal vertebrae, the bones of the forearm and hip. Frequent fractures after minor trauma, chronic back pain, loss of height, increased kyphosis, immobility, distorted body image, inability to perform activities of 
daily living thus resulting in depression are common presenting features. ${ }^{1}$

Measures most commonly applied for OP management are regular weight bearing exercises, oral calcium and Vitamin D supplementation and drugs which either decrease bone resorption or stimulates new bone formation. Drugs that decrease osteoclastic bone resorption are bisphosphonates (risedronate, alendronate, etc), Estrogen replacement therapy, Selective Estrogen Receptor Modulators (eg Raloxifene), Calcitonin, Strontium ranelate and Denosumab. ${ }^{5}$ Teriperatide, a congener of parathyroid hormone has been recently introduced as pulse therapy for OP and it has been shown to increase new bone formation. ${ }^{6}$ Despite of these modalities, OP has a profound negative impact on the Quality of Life (QoL) as pointed out by numerous studies. ${ }^{7}$ Therefore, it is necessary to evaluate physical functioning and psychosocial suffering of the patient along with the disease itself. Measurement of QoL not only helps in predicting clinical evolution of the disease, but also improves our understanding that can lead to developing better treatment plans. Furthermore, there is a paucity of Indian studies in this field. ${ }^{3,4}$ Hence the QoL evaluation of post-menopausal patients suffering from OP becomes imperative. To measure quality of life is to assess subjective feelings objectively and can be best accomplished by use of standardized questionnaires. ${ }^{8}$ The Quality of Life Questionnaire of the European Foundation for Osteoporosis (QUALEFFO) is the OP specific questionnaire most commonly used in the literature and focuses on patients with vertebral deformities. The 31-item QUALEFFO was developed as a shortened version of the QUALEFFO-41 and consists of three domains (pain, physical function, and mental state). ${ }^{7}$ This questionnaire has proven to be reproducible, practical, effective and globally validated and most extensively tested, therefore, we decided to use this questionnaire. ${ }^{8}$ Authors aimed to study the drug utilization pattern and to analyze Quality of life of postmenopausal women suffering from osteoporosis.

\section{METHODS}

The study was started after obtaining permission from the Indian Council of Medical Research and the Institutional Ethics Committee. This analytical cross-sectional study of 8 weeks duration was carried out in the Out-patient unit of Orthopedics department at a tertiary care teaching hospital in India. All the women who presented between May and June 2018with clinical features of OP and diagnosed with OP (with or without fractures) were included into the study after obtaining their written informed consent in the vernacular language. Women who suffered from any comorbid conditions known to affect QoL (E.g.- chronic depression, rheumatoid arthritis, etc.) were excluded from the study. Patients who were unable to understand questions of the questionnaire or who suffered from secondary osteoporosis were also excluded.

Pre-validated QUALEFFO-31 QoL questionnaire (in vernacular language) was administered to each patient enrolled into the study. There are 3 domains viz-pain, physical function and mental function. Responses of each of the 31 questions were analyzed. The scores were calculated according to published scoring algorithm of QUALEFFO-31. ${ }^{9}$ Each question in the questionnaire has 4 or 5 options with scores ranging from 1-5. All the answers are standardized so that 1 represents the best and 5 (or 4) represents the worst quality of life (reverse scores on questions 25, 26, 27, 28 and 30). Hence, higher score represents worse the QoL. Domain scores were calculated by averaging the answers of one domain and transforming the scores to a 100 point score. The total score was calculated by summing all answers of questions 1-31 and then transformed to scores from 0 to 100. Total Qualeffo score $=($ Actual score - lowest possible score/ range $) \times 100$. The domain score as well as total Qualeffo score was then compared between patients who were on different treatment plans. The collected data was analyzed using SPSS software version 23 and windows excel 2013. P value $\leq 0.05$ was considered as statistically significant.

\section{RESULTS}

A total of 91 post-menopausal osteoporotic patients were enrolled in our study. The mean age of participants was $56.2 \pm 6.6$ years. The average duration since menopause was $8.2 \pm 5.1$ years. Back pain followed by knee and shoulder pain was the most common presenting complaint (Figure-1). Out of 91 patients, 19 patients gave a history of one fracture, while 5 patients had developed 2 fractures in the past.

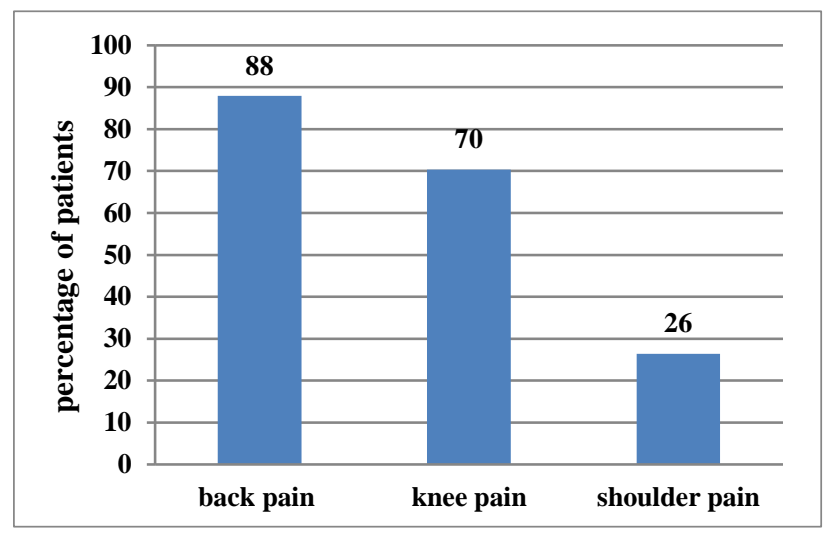

Figure 1: Clinical presentation with chief complaints.

All the patients received daily calcium $(500 \mathrm{mg}$ ) and vitamin D3 (250 I.U.) supplementation. All the patients additionally received any one of the analgesic preparation (paracetamol with tramadol or aceclofenac or ibuprofen or diclofenac) for pain relief. Group 1 consisted of sixty patients out of 91 , who did not receive any specific drug for OP. The reasons for not availing OP specific treatment cited were patient preference, not affordable, clinical discretion of the treating clinician.

But, nearly one-third $(\mathrm{n}=31)$ of the patients received one of the bispohosphonates for OP and these patients comprised of group 2. Risedronate (35 mg oral once a week) was most 
prescribed bisphosphonate $(21 \%)$, followed by alendronate (70 mg once a week oral) (5.4\%), ibandronate (4.3\%) $(150 \mathrm{mg}$ once a month oral) and zolendronate $(5 \mathrm{mg}$ intravenous drip once a year) $(2.1 \%)$. (Figure-2) Out of 91 patients, 42 (46\%) patients had started drug treatment within a month. Mean \pm SD for duration of treatment was 2.75 \pm 3.3 .

QUALEFFO-31 measures 3 domains: PAIN (4 items; Questions 1 to 4), PHYSICAL FUNCTION (17 items; Questions 5 to 23) and MENTAL FUNCTION (9 items; Questions 24 to 31). Score of each question, domain wise score and grand score was calculated as presented. These scores were then compared between group 1 and group 2 (Figure 3). All the patients experienced included in the study experienced some degree of pain. The overall mean score of pain domain was $62.84 \pm 16.28$. Patients in group 1 had significantly lower pain score $(58.5 \pm 13.5)$ as compared to group $2(71.1 \pm 18)$, p value 0.0003 . Overall

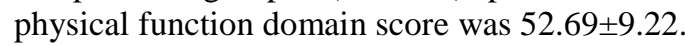

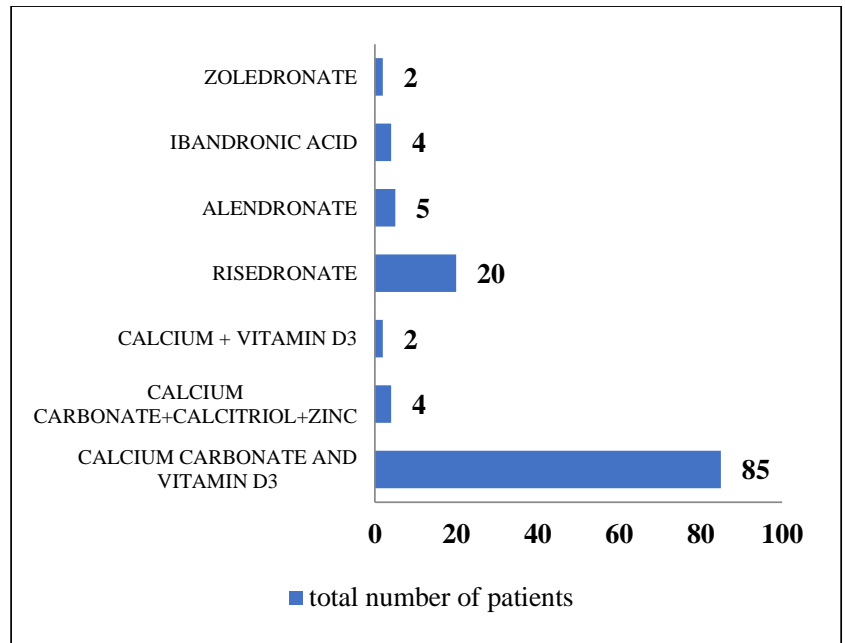

Figure 2: Most frequently prescribed drugs for Osteoporosis.

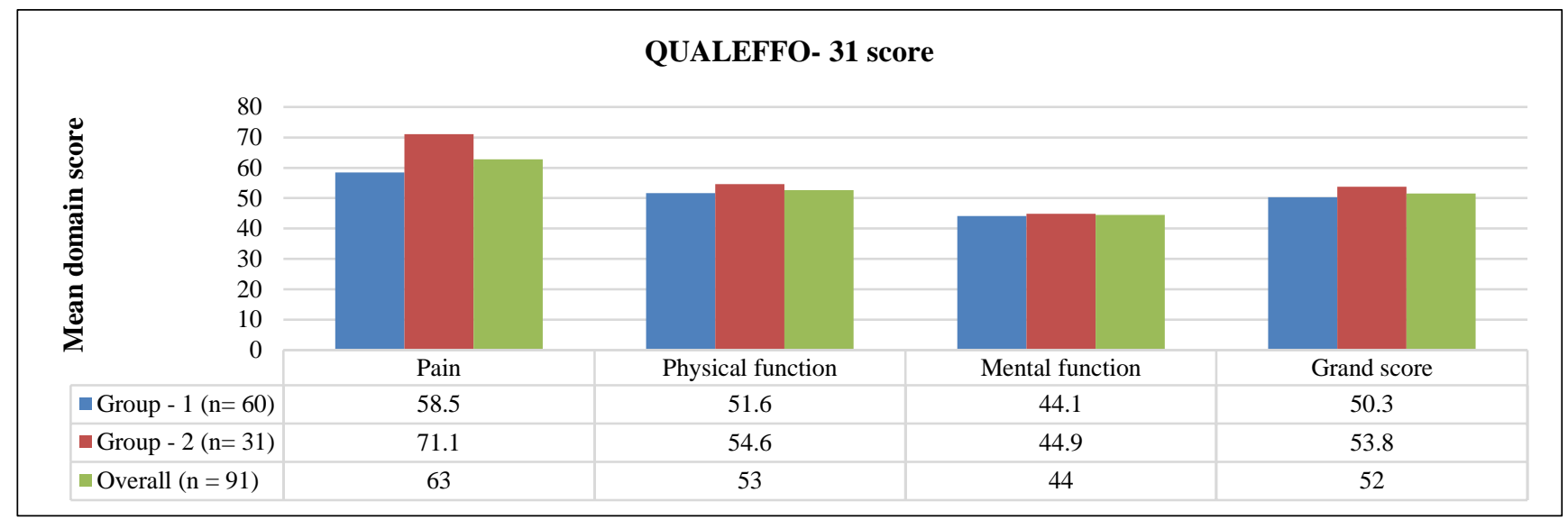

$* * \mathrm{p}$ value is $<0.05$ i.e. significant

Figure 3: QUALEFFO-31 score.

Patients in group 1 had score of $51.66 \pm 7.58$ and that of group- 2 was $54.68 \pm 11.67$, the difference being not significant ( $\mathrm{p}$ value $=0.13$ ). Overall mental domain function score was $44.4 \pm 9.9$. Patients in group-1 had score of $44.17 \pm 8.54$ and that of group- 2 was $44.98 \pm 12.47$, the difference being not significant ( $p$ value $=0.71$ ). Mean \pm SD of grand score was $51.54 \pm 8.2$. The score of group-1 was $50.33 \pm 6.8$ and that of group- 2 was $53.89 \pm 10.2$. The difference between the groups was statistically significant ( $\mathrm{p}$ value $=0.05)$.

\section{DISCUSSION}

Osteoporosis is a metabolic bone disease that can result in impairment of physical, emotional, and social spheres of a patient's life, thus affecting patient's perceived quality of life. In the present study, a total of 91 postmenopausal females diagnosed with OP were enrolled. All the patients received calcium and vitamin D supplementation and one of the nonsteroidal anti-inflammatory drugs as analgesic. Sixty of them formed group 1 . The remaining 31 patients, who additionally received any one of the bisphosphonate, were considered as group 2. In our study, Risedronate $(88.2 \%)$ was most commonly prescribed bisphosphonate, followed by alendronate $(5.4 \%)$, ibandronate $(4.3 \%)$ and zolendronate $(2.1 \%)$. This is unlike the study done in Kasturba Medical College, Manipal University which reported that alendronate was most commonly prescribed in India. ${ }^{8}$ None of the patients in our study were prescribed other modalities of treatment like SERM, calcitonin, strontium renolate, denosumab or teriperatide. This is strikingly in contrast to the western scenario, where majority of the patients diagnosed with OP receives specific anti-osteoporotic treatments like bisphosphonate or SERM. ${ }^{9}$ The possible explanation could be that in India specific anti-osteoporotic treatment is reserved for those who have severe clinical presentation and /or who 
can afford the high cost therapies. Another important factor is the risk of atypical fractures and delayed healing due to long term use of bisphosphonates as reported by many foreign studies. An Indian study on adherence to anti OP treatment suggested that even after starting the treatment, many patients stopped the treatment due to its high cost. This could have impacted physician's prescribing pattern. ${ }^{10,11}$

In our study, the mean age group of presenting patients was $56.2 \pm 6.6$ years. The mean duration since menopause among these patients was $8.2 \pm 5.1$ years. This is in parallel to a study conducted in Postgraduate Institute of Medical Education and Research at Chandigarh which stated that the mean age group

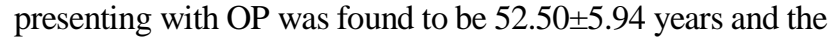
average period since menopause was $5.06 \pm 3.8$ years. ${ }^{12}$ However, western studies found that the peak of incidence of OP was in the age group of 70-80years, which suggests that the onset of disease in India is earlier. ${ }^{13}$

Pain was the most common presenting feature in our study. We found that almost all the patients $(88 \%)$ in our study had some degree of back pain. Chronic back pain could be the result of underlying undiagnosed vertebral fracture. Other studies have also reported that vertebral fractures are most common presenting feature of OP. ${ }^{14}$ In our study we observed that the pain domain was affected the most which is like a study done in Poland. ${ }^{15}$ The mean score of pain domain $(n=91)$ was $62.84 \pm 16.28$. Patients in group-1 had significantly lower pain score $(58.5 \pm 13.5)$ as compared to group $2(71.1 \pm 18), \mathrm{p}$ value $=0.0003$. Higher pain domain score in group 2 as compared to group 1 could be attributed to the fact that most of the patients in group 2 (23 out of 31) had started treatment with bisphophonates within one month of administration of QoL. It is likely that as the severity of complaints of pain increased, they were given the bisphosphonates in addition to calcium supplementation despite the economic burden.

An elevated mean physical domain function score $(52.69 \pm 9.22)$ could be related with pain and deformity secondary to fractures. Similar studies commented that the functional impairment resulting from vertebral fractures was substantial and reduced the ability to perform both daily household and self-care activities. ${ }^{15,16}$ Patients in group -1 (score of 51.66 \pm 7.58$)$ and group- $2(54.68 \pm 11.67)$ had similar scores ( $p$ value $=0.13$ ) and faced similar severity of problems in their day-to-day lives like dressing, bathing and cleaning, using washroom, cooking, cleaning dishes, etc.

Mean mental domain function score was 44.4 \pm 9.9 . This was in accordance to a QoL study done in San Paolo Hospital in Italy which concluded that patients with osteoporosis, even in the absence of fractures, had a more depressed mood and a lower quality of life than that of the control group. ${ }^{17}$ Patients in group-1 had score of $44.17 \pm 8.54$ and that of group- 2 was $44.98 \pm 12.47$, the difference being not significant ( $p$ value $=0.71$ ). Patients in both groups felt tired, downhearted, lonely, less energetic, upset over little things, faced difficulty in communicating with people and felt low spirited. $13.3 \%$ patients in grp- 1 and $51.6 \%$ patients in grp- 2 reported their quality of life as below satisfactory $(\mathrm{p}<0.05) .61 .3 \%$ patients in group-2 were more hopeful for a better future while only $33 \%$ in group 1 felt the same $(\mathrm{p}<0.05)$. As the patients receiving bisphosphonates are spending more on treatment than the group receiving only calcium they may feel that they are getting better treatment and hence are more hopeful about their future.

The Mean \pm SD of Grand qualeffo score was $51.54 \pm 8.2$ suggesting decline in QoL in all the aspects. The score of group 1 was $50.33 \pm 6.8$ and that of group-2 was $53.89 \pm 10.2$. The difference between the groups was statistically significant ( $\mathrm{p}$ value $=0.05$ ).

Thus, OP leads to severe discomfort and/or disability and disturbs personal life owing to chronic pain, reduced physical and social activity and affective symptoms like low mood and anxiety.

Limitations of the study authors understand that our study is of short duration and with limited number of patients.

\section{CONCLUSION}

The results of our study stated that even though Bisphosphonates are first choice of drugs for OP, they are less routinely used in our setup. Patients who were recently started on bisphosphonates reported worse score in all the domains in comparison to patients who received only calcium and vitamin supplementation. It is likely that bisphosphonates might need more time to show considerable effect or because it was added only to those patients who already had more complaints and could afford the high cost. OP among postmenopausal women causes pain and physical debilitation that compromises their ability to carry out day to day tasks at a normal efficiency and in turn has detrimental effect on mental health as evident on patient's perceived QoL score.

\section{Funding: Partial funding by Indian Council of Medical Research (ICMR) \\ Conflict of interest: None declared \\ Ethical approval: The study was approved by the Institutional Ethics Committee}

\section{REFERENCES}

1. Teng GG, Curtis ER, Saag KG. Mortality and osteoporotic fractures: is the link causal, and is it modifiable? Clin Exp Rheumatol. 2008:26(50):125-37.

2. Kanis JA, World Health Organization Scientific Group. WHO technical report. University of Sheffield, UK. 2007;66.

3. Malhotra, A and Mithal, A. Osteoporosis in Indians. Indian J Med Res. 2008:127;263-8.

4. Marwaha RK, Tandon N, Garg MK, Kanwar R, Narang A, Sastry A, et al. Bone health in healthy Indian population aged 50 years and above. Osteoporos Int. 2011;22:2829-36 
5. Emkey R. Alendronate and risedronate for the treatment of ostmenopausal osteoporosis: clinical profiles of the once-weekly and once-daily dosing formulations. Med Gen Med. 2004Jul19;6(3):6.

6. Han SL, Wan SL. Effect of teriparatide on bone mineral density and fracture in postmenopausal osteoporosis: meta-analysis of randomised controlled trials. Int J clin practice. 2012 Feb;66(2):199-209.

7. Lips P, van Schoor NM. Quality of life in patients with osteoporosis.Osteoporos Int. 2005;16(5):447-55.

8. Wilson S, Sharp CA, Davie MW. Health-related quality of life in patients with osteoporosis in the absence of vertebral fracture: a systematic review. Osteoporos Int. 2012Dec;23(12):2749-68.

9. Van Schoor NM, Knol DL, Glas CA, Ostelo RW, Leplège $\mathrm{A}$, Cooper $\mathrm{C}$, et al. Development of the Qualeffo-31, an osteoporosis-specific quality-of-life questionnaire. Osteoporos Int. 2006;17(4):543-51.

10. Tripathy A, Adiga S, Shah HH, Shanbhag TV, Mahesh Kumar D. A retrospective study of clinical profile and drug prescribing pattern in osteoporosis in a tertiary care hospital. Int $\mathrm{J}$ Pharmacy and Pharmaceutical Sciences. 2015Jan1;7(10):3903.

11. Cortet B, Blotman F, Debiais F, Huas D, Mercier F, Rousseaux C, et al. Management of osteoporosis and associated quality of life in post-menopausal women. BMC Musculoskelet Disord. 2011Jan12;12:7.

12. Schneider JP. Should bisphosphonates be continued indefinitely? An unusual fracture in a healthy woman on long-term alendronate. Geriatrics. 2006;61:(1):31-3.

13. Tandon VR, Sharma S, Mahajan S, Mahajan A, Khajuria V, Gillani Z. First Indian prospective randomized comparative study evaluating adherence and compliance of postmenopausal osteoporotic patients for daily alendronate, weekly risedronate and monthly ibandronate regimens of bisphosphonates. J Midlife Health. 2014Jan;5(1):29-33.

14. Aggarwal N, Raveendran A, Khandelwal N, Sen RK, Thakur JS, Dhaliwal LK, et al. Prevalence and related risk factors of osteoporosis in peri- and postmenopausal Indian women. Journal of Mid-Life Health. 2011;2(2):81-5.

15. Shivakumar V, Sudhir G, Priyadarshini SP, Shanmugam M, Relationship Between Osteoporosis and Periodontitis. Chettinad Health City Medical J. 2012;1(1):19-27.

16. Wong CC, McGirt MJ. Vertebral compression fractures: a review of current management and multimodal therapy. J Multidisciplinary Healthcare. 2013;6:205-14.

17. Bączyk G, Opala T, Kleka P. Quality of life in postmenopausal women with reduced bone mineral density: psychometric evaluation of the Polish version of QUALEFFO-41. Archives of Medical Science: AMS. 2011;7(3):476-85.

18. Xenodemetropoulos T, Davison S, Ioannidis G, Adachi JD. The impact of fragility fracture on healthrelated quality of life : the importance of antifracture therapy. Drugs Aging. 2004;21(11):711-30.

19. Bianchi ML, Orsini MR, Saraifoger S, Ortolani S, Radaelli G, Betti S. Quality of life in post-menopausal osteoporosis. Health and Quality of Life Outcomes. 2005;3:78

Cite this article as: Agrawal SP, Patel SV, Malhotra S, Patel PR. Evaluation of prescription pattern and quality of life in post-menopausal osteoporosis: a cross sectional study. Int J Basic Clin Pharmacol 2019;8:1861-5. 